\title{
Mastite com septicemia em caninos causada por Staphylococcus intermedius
}

\author{
Mastitis with sepsis in dogs due to Staphylococcus intermedius \\ Luciane Martins Borowsky ${ }^{1}$, David Driemeier ${ }^{2}$, Daniela Bernadete Rozza ${ }^{1}$ \& \\ Marisa Ribeiro de Itapema Cardoso ${ }^{3}$
}

\begin{abstract}
RESUMO
Os casos de mastite em caninos ocorrem mais comumente no período pós-parto ou como complicação de casos de pseudociese. Os microrganismos mais isolados nestes casos têm sido enterobactérias, estreptococos e estafilococos. Neste relato, são descritos três casos de cães com mastite aguda que evoluíram para óbito. Os animais apresentavam vômitos, abatimento, dificuldade respiratória e hálito urêmico. Na necropsia havia mastite gangrenosa e abscessos mamários nas mamas abdominais caudais e inguinais. No exame histopatológico, encontrou-se extensas áreas de necrose e hemorragia associadas à inflamação purulenta e presença de cocos gram positivos. Trombos sépticos foram encontrados em órgãos parenquimatosos. As glândulas mamárias com lesão macroscópica foram encaminhadas para exame bacteriológico. Houve crescimento de colônias circulares, lisas, brilhantes e com presença de hemólise parcial e total no ágar sangue. Em todos os casos relatados, foi isolado o Staphylococcus intermedius, que é o principal representante do grupo dos agentes bacterianos coagulase positivos encontrados em cães. Apesar de não ser possível descartar a hipótese de uma bacteremia, os casos observados podem estar associados à produção de toxinas. Este relato objetiva levantar a hipótese de associação de toxinas com os casos aqui descritos.
\end{abstract}

Descritores: mastite, canino, Staphylococcus intermedius.

\begin{abstract}
Canine mastitis commonly occurs during early postpartum or as a complication of pseudopregnancy. The enterobacteriaceae, streptococci and staphylococci are among the microorganisms more frequently isolated from cases of canine mastitis. In this report, three clinical cases involving bitches that succumbed to acute mastitis are described. Common symptoms were vomiting, dyspnea and uremic breath. The caudal abdominal and inguinal mammary glands were swollen and dark red. Gross mammary lesions included subcutaneous edema, and necrotic and hemorrhagic areas. Histological findings included extensive hemorrhagic and necrotic areas associated with suppurative inflammation, with the identification of gram positive bacteria in the necrotic areas. Septic thrombi could also be observed in several parenchymatous organs. Mammary glands with macrocospic lesions were sampled for a bacteriological screening. Growth of circular, smooth, and shining colonies was observed, with partial and total hemolysis in the agar blood. Staphylococcus intermedius was isolated from the affected mammary glands from all animals. S. intermedius isolates with coagulase activity is the main representative group of bacterial agents normally isolated from mastitis in dogs. We hypothesize that the clinical evolution seen in mastitic patients is likely to be associated with toxemic conditions, but bacteremia should also be considered during the progression of the infection.
\end{abstract}

Key words: mastitis, canine, Staphylococcus intermedius.

\footnotetext{
${ }^{1}$ Programa de Pós-graduação em Ciências Veterinárias (PPGCV), Faculdade de Veterinária (FAVET) de Porto Alegre, Universidade Federal do Rio Grande do Sul (UFRGS). ${ }^{2}$ Setor de Patologia Veterinária. ${ }^{3}$ Setor de Medicina Veterinária Preventiva - FAVET/UFRGS. CORRESPONDÊNCIA: M.R.I. Cardoso [mcardoso@vortex.ufrgs.br ; Fax: + 5551 3316-7305].
} 


\section{INTRODUÇÃO}

Os casos de mastite em caninos ocorrem mais comumente no período pós-parto ou como complicação de casos de pseudociese. Os microrganismos mais isolados nestes casos têm sido enterobactérias, estreptococos e estafilococos[6]. Os sinais clínicos mais comuns são edema, hiperemia e dor no local, além de perda de apetite e relutância em amamentar os filhotes. Apesar de o quadro clínico poder evoluir para abscedação e mastite gangrenosa, geralmente o prognóstico para a fêmea é favorável. No presente trabalho são relatados três casos de mastite em cães que evoluíram para óbito.

\section{MATERIAIS E MÉTODOS}

Os três animais haviam sido atendidos no Hospital de Clínicas Veterinárias, entre março e junho de 2003, e pertenciam a proprietários diferentes. O primeiro animal não tinha raça definida (SRD) estava com 2 anos de idade e havia parido há cerca de um mês. O segundo caso era uma fêmea da raça fila, com 7 anos de idade e o terceiro caso um animal SRD também de 7 anos de idade. Não havia relato de parto recente ou pseudociese em ambos os casos. Os animais estavam com sinais de mastite, dificuldade respiratória, hálito urêmico, abatimento e apresentavam vômitos. Aproximadamente uma semana após o aparecimento dos sintomas, as três fêmeas vieram a óbito. Apenas a fêmea do terceiro caso havia sido tratada com diclofenaco sódico; em nenhum dos casos havia sido feita antibioticoterapia. A necropsia e exames histopatológico, incluindo coloração de Gram foram efetuado. As glândulas mamárias com lesão macroscópica e a amostra de sangue, obtida por punção cardíaca, da terceira fêmea foram encaminhadas para exame bacteriológico. Ambos os materiais foram semeados em ágar sangue ovino a $5 \%$ e ágar Mac Conkey. Após incubação a $37^{\circ} \mathrm{C}$ por até 48 horas, procedeu-se à identificação das bactérias conforme descrito[3]. As bactérias isoladas foram testadas quanto a sua resistência a antimicrobianos pela técnica de difusão em ágar [3], utilizando-se discos impregnados com gentamicina $(10 \mathrm{mg})$, tetraciclina $(30 \mathrm{mg})$, oxacilina (1mg), sulfa trimetoprima $(25 \mathrm{mg})$, nitrofurantoína $(300 \mathrm{mg})$, estreptomicina $(10 \mathrm{mg})$, cloranfenicol (30mg), neomicina (30mg) e ampicilina (10mg).

\section{RESULTADOS}

Na necropsia, todos os animais apresentaram lesões de mastite gangrenosa com áreas de tecido necrótico e hemorrágico, formando abscessos envolvendo as mamas abdominais caudais e inguinais. Além disso, observou-se depósitos de fibrina sobre a cápsula do fígado e congestão pulmonar. No exame histopatológico, havia uma mastite purulenta com áreas de trombose e hemorragias envolvendo as mamas e tecidos adjacente. Havia formação de abscessos em algumas áreas. Bactérias Gram positivas puderam ser visualizadas presentes nas mamas e em trombos localizados em diversos órgãos. A partir do material coletado da glândula mamária dos três animais houve crescimento de colônias circulares, lisas, brilhantes e com presença de hemólise parcial e total no ágar sangue. Na coloração de Gram, visualizaram-se cocos Gram positivos, sem arranjo definido. A bactéria isolada mostrou-se catalase positiva, oxidase negativa, coagulase positiva, "clumping factor" positiva, urease positiva e Voges-Proskauer negativa. A partir disto, foi possível identificá-la como Staphylococcus intermedius. O bacteriológico de sangue obtido por punção cardíaca foi negativo. No antibiograma todas as amostras foram sensíveis aos antimicrobianos testados.

\section{DISCUSSÃO E CONCLUSÕES}

O Staphylococcus intermedius é o principal representante do grupo dos agentes bacterianos coagulase positivos encontrados em cães[1]. Apesar de existirem relatos do Staphylococcus intermedius como causador de mastite [2], esta bactéria está mais associada a casos de pioderma e otite externa em cães[3]. Não têm sido comum o diagnóstico em cadelas na Faculdade de Veterinária-UFRGS.

Os três casos de mastite relatados apresentaram-se sem associação com parto recente, como tem sido geralmente relatado[5].

Nos três casos foram encontrados acúmulos bacterianos em outros tecidos. Apesar de não ser possível descartar a hipótese de uma bacteremia, os casos observados podem estar associados à produção de toxinas bacterianas no sítio da infecção. Em humanos, um quadro caracterizado por febre alta, dor de cabeça, confusão mental, edema subcutâneo, vômito, diarréia e 
choque hipotensivo tem sido associado ao Staphylococcus aureus. Em casos mais severos têm sido relatada a ocorrência de falha renal, coagulação intravascular disseminada, gangrena e morte. Estes casos têm sido associado a linhagens de $S$. aureus produtores da Toxina da Síndrome do Choque Tóxico (TSST) [7]. Esta toxina já foi encontrada em amostras de Staphylococcus intermedius isoladas de pioderma canino, tanto sozinha quanto associada com enterotoxinas[4]. Desta forma, é possível levantar a hipótese de associação de toxinas com os casos aqui relatados. Observou-se, ainda, que as amostras não apresentaram resistência aos antimicrobianos testados. Provavelmente o diagnóstico precoce da mastite e o esta- belecimento de antibioticoterapia adequada teria sido eficiente na reversão dos quadros. No entanto observou-se que houve manifestação sistêmica do agente causando hemorragias, e trombose em vários órgãos o que provavelmente se deve à produção de toxinas e septicemia, o que pode dificultar o tratamento.

A formação de abscessos indica que os casos eram crônicos. A via de acesso dos agentes bacterianos, provavelmente, tenha sido mamária, pelo fato de afetar apenas algumas mamas e não a totalidade. Neste sentido, a ocorrência de infecção nas mamas caudais é a mais comum [6] Os três casos de mastite aguda que cursaram com septicemia em cães foram causados pelo Staphylococcus intermedius.

\section{REFERÊNCIAS}

1 Berg J. N., Wendell, D. E., Vogelweid C. \& Fales W. I. 1984. Identification of the major coagulase-positive Staphylococcus sp. of dogs as Sthaphylococcus intermedius. American Journal of Veterinary Research. 45: 1307-1309.

2 Carter G. R. 1988. Estafilococos.In: Fundamentos de Bacteriologia e Microbiologia Veterinária. São Paulo: Roca, pp.114-117.

3 Carter M.E., Quin P.J., Markey B. \& Carter G.R. 1994. Bacteriology. In: Clinical Veterinary Microbiology. London: Mosby, pp. 118-126.

4 Hendrick A., Schubertii H., Schueler K. \& Lloyd D. I. 2002. Frequency of superantigen-producing Staphylococcus intermedius isolates from canine pyoderma and proliferation-inducing potential of superantigens in dogs. Research in Veterinary Science. 73: 273-277.

5 Johnston S. D. 1984. Distúrbios não neoplásicos das glândulas mamárias. In:. Kirk R. (Ed). Atualização em Terapêutica Veterinária: Pequenos Animais. 5. ed. São Paulo: Manole, pp. 1365-1367.

6 Jung C., Wehrend A., Konig A. \& Bosted H. 2002. Investigation about the incidence, differention and microbiology of canine mastitis. Praktische Tieraszt. 83: 508-511.

7 Smith G. R. \& Easman C. S. F. 1990. Staphylococcal diseases. In: Principles of Bacteriology, Virology and Immunity. 8th edn. London: Great Britain, pp. 215-238.

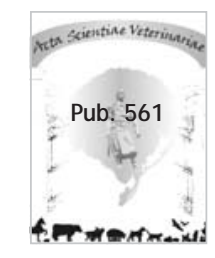


